To preview AHRQ's MCC video and the MCC infographic, please visit: http://www.ahrq.gov/ professionals/prevention-chronic-care/decision/mcc/.
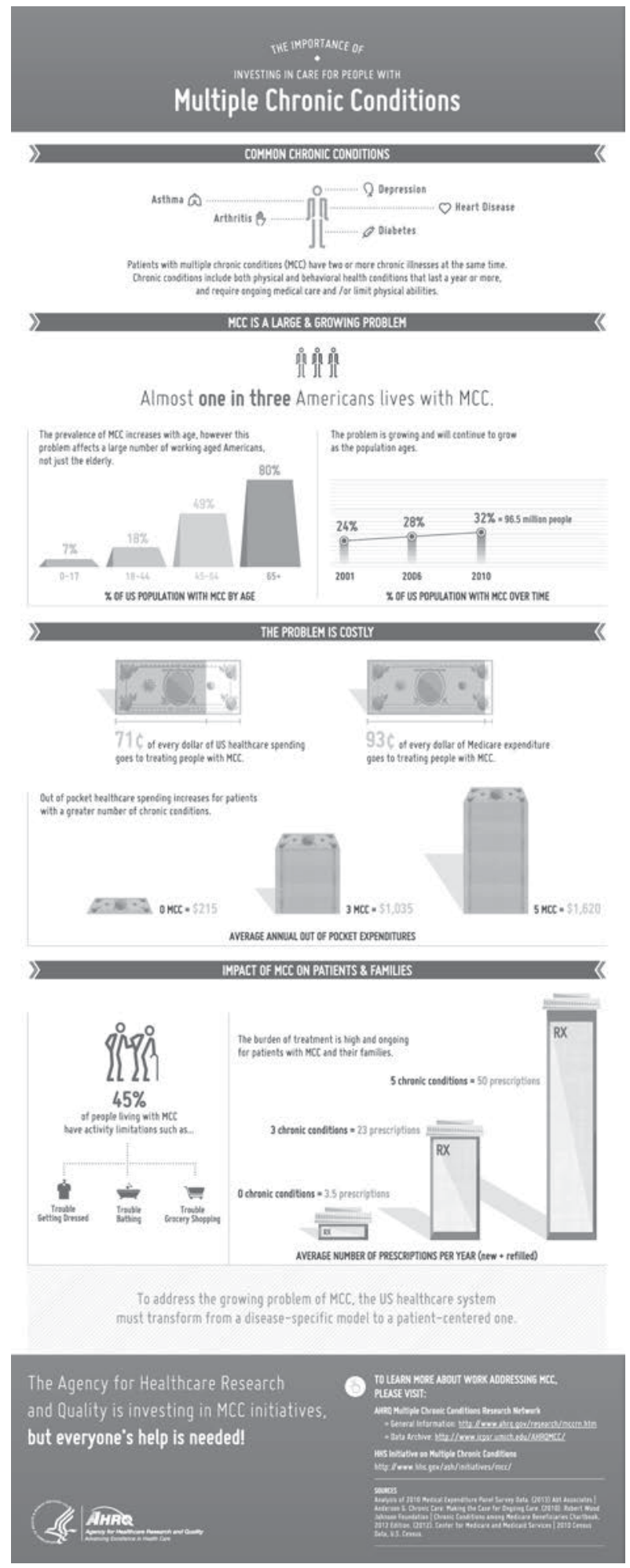

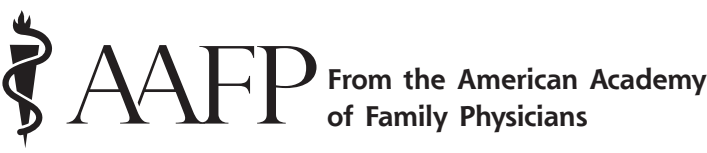

Ann Fam Med 2014;178-179. doi: 10.1370/afm.1637.

\section{AMERICANS WANT PHYSICIANS HANDLING THEIR HEALTH CARE}

Family physicians recently received one of the best possible gifts from the American public - a huge "thumbs up" and vote of confidence as to whom they want overseeing their health care.

That's the headline news pulled from survey results recently released that indicate

- $72 \%$ of American adults prefer physicians to nonphysicians when it comes to health care

- $90 \%$ of adults would choose a physician to lead their "ideal medical team" when given the choice

- By a greater than two-to-one margin, adults see physicians and family physicians as more knowledgeable, experienced, trusted and up-to-date on medical advances than nonphysicians

AAFP President Reid Blackwelder, MD, of Kingsport, Tennessee, called the news "outstanding."

"It's exciting, because anytime you get a survey that overwhelmingly says patients appreciate you and want to see you, that's good news," said Blackwelder. "I see this as personal affirmation. Our patients value us. They trust us."

Blackwelder said the survey results accomplished something legislators and policymakers have been unable to do despite their constant talk about the value of primary care. "This survey puts a face-a family physician face-on the message that's being repeated nationwide that team-based care and primary care are critical to the successful transformation of health care delivery in this country," said Blackwelder.

"Even in these challenging times, we universally are seen as knowledgeable and trustworthy; our patients want to see us when they have health care needs, and overwhelmingly, they want us to be the leader of their health care team," he added.

In a related press release, Blackwelder detailed exactly what patients value in their physicians. "They understand that physicians have the medical expertise necessary to know whether an apparently simple symptom signals a complication of a chronic condition, the onset of a new condition affecting multiple organs, or a short-term and easily treated problem," said Blackwelder. "They want that expertise for themselves and their loved ones."

The AAFP-commissioned survey was conducted online November 8-15, 2013 by Ipsos, a global market 
research company, and included responses from 1,320 US adults aged 18 years or older.

The survey asked consumers a series of questions about health care topics, including, for example, who they most often see for their health care, who they would prefer to see if given the choice and what characteristics they would ascribe to various health care professionals.

The survey defined the term "medical team" and supplied a list of various health care professionals: nurse practitioners (NPs), physician assistants (PAs), internists, pediatricians, chiropractors, surgeons, physicians, and primary care physicians.

Respondents then were asked which professional on that list was their "first call" when a medical question arose, and $41 \%$ indicated that they wanted to confer with their primary care physician. Some of the other responses were physician (24\%), specialist (8\%), NP $(6 \%)$, and PA (3\%).

In addition, $70 \%$ of the adults surveyed said they were less likely to vote for a state representative who supported legislation that would restrict their ability to continue seeing their physician, $72 \%$ indicated they would be more likely to vote for a representative who would protect consumers' ability to continue to see their physician.

Blackwelder summarized the findings this way: "Finally, we have a survey from patients that says they not only value primary care, they value you for your education, expertise and experience.

"As family physicians, we not only are a critical part of the health care team, we are the identified leader of the team, and that's what our patients want and expect."

AAFP News Now

From the American

Board of Family Medicine at the University of Texas Health Science Center at San Antonio. He is a bicultural researcher and research ambassador to Latin America who advises US federal agencies developing health prevention projects for US Hispanic communities. Dr. Jaén also led the evaluation of the first national Patient-centered Medical Home demonstration. He continues to practice outpatient and inpatient medicine.

The Institute of Medicine (IOM) is unique in its structure as both an honorific membership organization and an advisory organization. Established in 1970 by the National Academy of Sciences, IOM has become recognized as a national resource for independent, scientifically informed analysis and recommendations on health issues. Fewer than 2,000 physicians are elected members, and just 70 US physicians are invited to join each year. The National Academy of Sciences was created by President Lincoln in 1863 .

Robert Pbillips, MD, MSPH, American Board of Family Medicine

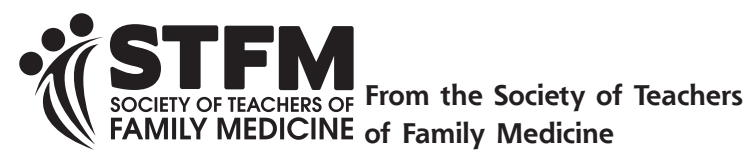

Ann Fam Med 2014;179-180. doi: 10.1370/afm.1632.

\section{STFM DEVELOPS PRECEPTOR GUIDELINES AND A POSITION STATEMENT ON STUDENT USE OF ELECTRONIC HEALTH RECORDS}

The Society of Teachers of Family Medicine has created 2 documents to help preceptors and other educators when working with students using electronic health records (EHRs). The guidelines will help preceptors work effectively with students when using EHRs. The position statement will assist preceptors and other educators when engaging compliance officers or organizations in discussions about the need for medical students to work meaningfully with electronic medical records.

\section{Preceptor Guidelines}

Medical students need to learn effective use of EHRs to prepare them for their work as residents and practicing physicians. This document reviews core medical student documentation issues and highlights core EHR concepts, functions, and skills to which we believe all medical students should have exposure and in which they should begin developing competence. As clinical preceptors we believe that actively considering these concepts and exposing your students to these concepts 